Check for updates

Cite this: Phys. Chem. Chem. Phys., 2020, 22, 18435

Received 24th January 2020 Accepted 4th July 2020

DOI: $10.1039 / \mathrm{d} 0 \mathrm{cp} 00417 \mathrm{k}$

rsc.li/pccp

\section{X-ray Raman scattering for bulk chemical and structural insight into green carbon $\dagger$}

\author{
Luke J. R. Higgins, (D)*a Christoph J. Sahle, (D) ${ }^{b}$ Mahalingam Balasubramanian (D) ${ }^{c}$ \\ and Bhoopesh Mishra (iD *a
}

$X$-ray Raman scattering (XRS) spectroscopy is an emerging inelastic scattering technique which uses hard $X$-rays to study the X-ray absorption edges of low-Z elements (e.g. C, N, O) in bulk. This study applies XRS spectroscopy to pyrolysis and hydrothermal carbons. These materials are thermochemicallyproduced carbon from renewable resources and represent a route for the sustainable production of carbon materials for many applications. Results confirm local structural differences between biomassderived (Oak, Quercus Ilex) pyrolysis and hydrothermal carbon. In comparison with NEXAFS, XRS spectroscopy has been shown to be more resilient to experimental artefacts such as self-absorption. Density functional theory XRS calculations of potential structural sub-units confirm that hydrothermal carbon is a highly disordered carbon material formed principally of furan units linked by the $\alpha$ carbon atoms. Comparison of two pyrolysis temperatures $\left(450{ }^{\circ} \mathrm{C}\right.$ and $650{ }^{\circ} \mathrm{C}$ ) shows the development of an increasingly condensed carbon structure. Based on our results, we have proposed a semi-quantitative route to pyrolysis condensation.

\section{Introduction}

Production of value-added biorenewable materials and chemicals from biomass has regained significant attention over the last decade as a way to move away from petroleum-based products. One vector of biorenewables development is green carbon; carbon materials produced thermochemically from sustainable resources including biomass. It is thought that green carbons will prove more sustainable, effective and efficient in applications essential to developing sustainable economies - namely catalysis, energy storage, agronomy and water/air purification. ${ }^{1-4}$ Pyrolysis and hydrothermal carbonisation are two thermochemical conversion processes that have emerged as key conversion routes from biomass to green carbon. Hydrothermal carbonisation (HTC), is the thermochemical conversion of an organic feedstock in a hot, auto-compressed environment (e.g. $\left.250{ }^{\circ} \mathrm{C}, 50 \mathrm{bar}\right)$, and forms a chemical-rich process water and a solid carbonaceous product known as hydrothermal carbon or hydrochar. Similarly, pyrolysis carbon is formed during pyrolysis, the thermal decomposition of biomass in an inert atmosphere, at temperatures between $400{ }^{\circ} \mathrm{C}$ to $700{ }^{\circ} \mathrm{C}$. Future successful application of green

\footnotetext{
${ }^{a}$ School of Chemical \& Process Engineering, University of Leeds, Leeds, UK. E-mail: B.Mishra@leeds.ac.uk; Tel: +44 (0)113 3436737

${ }^{b}$ European Synchrotron Radiation Facility, avenue des Martyrs, Grenoble, France

${ }^{c}$ Advanced Photon Source, Argonne National Laboratory, Argonne, IL, USA

$\dagger$ Electronic supplementary information (ESI) available. See DOI: 10.1039/ d0cp00417k
}

carbon is dictated by the ability to engineer their key properties, namely: surface area, conductivity, morphology and functionality. ${ }^{4}$ Therefore, the utilisation of these materials is dependent on successfully engineering and understanding their carbon chemistry. Specifically, an understanding of bulk carbon chemistry in green carbons and the differences between bulk and surface carbon functionality is now crucial.

Pyrolysis and hydrothermal carbons are amorphous, high molecular weight carbonaceous materials with complex spectroscopic signatures. In order to study changes in carbon chemistry in hydrothermal and pyrolysis carbons, current literature relies on spectroscopy obtained ex situ by Fourier-transform infrared spectroscopy (FT-IR), ${ }^{5}$ X-ray photoelectron spectroscopy (XPS), ${ }^{6}$ soft X-ray absorption spectroscopy (NEXAFS) ${ }^{7,8}$ or solid-state Carbon NMR $\left({ }^{13} \mathrm{C}-\mathrm{NMR}\right) .{ }^{9}$ Increasingly, however, FT-IR, ${ }^{13} \mathrm{C}-\mathrm{NMR}$, XPS or NEXAFS are not sufficient to gain well-resolved, bulk, local structural information due to at least one of two limitations: surface bias and low sensitivity. ${ }^{13} \mathrm{C}$-NMR is currently the only route to bulk spectroscopy of green carbon, and has provided the first evidence for a furanic substructure in hydrothermal carbon ${ }^{9}$ and a measure of total aromatisation in pyrolysis carbon. ${ }^{10}$ However ${ }^{13} \mathrm{C}$-NMR suffers from inherent low sensitivity. Poor signal-to-noise ratios are due to (i) the low natural abundance $\left(1.1 \%\right.$ n.a) of the isotope ${ }^{13} \mathrm{C}$ and (ii) the large relaxation times required to generate quantitative spectra. Pulse sequencing, isotopic enrichment and correlation spectroscopy in ${ }^{13} \mathrm{C}$-NMR have been successfully applied to enhance spectral resolution, but such experiments are difficult to perform. ${ }^{11-13}$ Furthermore, in situ 
experimental studies using NMR are uncommon and highly challenging. X-ray spectroscopy (NEXAFS, XPS), infrared spectroscopy FT-IR or optical Raman spectroscopy, provide higher-resolution spectroscopic information than ${ }^{13} \mathrm{C}-\mathrm{NMR}$. Unfortunately, optical spectroscopy (Raman, FT-IR) is diminished due to inherent surface-sensitivity and the challenges in analysis beyond fingerprinting. Recent studies have shown NEXAFS to be a powerful tool for element-specific characterisation of local structure and chemistry in disordered carbon materials. ${ }^{8,14-16}$ For studies of carbon and heteroatoms (mainly $\mathrm{N}, \sim 410 \mathrm{eV} \& \mathrm{O}, \sim 543 \mathrm{eV}$ ), NEXAFS and XPS operate in the soft X-ray regime. The use of soft X-rays results in sub-micron path-lengths and a larger interaction cross-section which increases radiolysis, and results in highly surface sensitive measurements. Surface sensitivity is problematic since both hydrothermal and pyrolysis carbons have been shown to display different bulk to local-surface chemistry. ${ }^{17,18}$ The use of soft X-rays in NEXAFS and XPS also results in difficult sample preparation and challenging high-vacuum sample environments, which render in situ studies impractical. ${ }^{19}$

Herein, we present the case for X-ray Raman scattering (XRS) spectroscopy studies of bulk carbon chemistry in pyrolysis and HTC. This is done in comparison to NEXAFS carbon spectroscopy, collected for the same materials, in order to contrast and compare soft and hard X-ray spectra. Hydrothermal carbon produced at $250{ }^{\circ} \mathrm{C}$ (HTC-Oak-250) and pyrolysis carbon produced at $450{ }^{\circ} \mathrm{C}$ (Pyro-Oak-450) from oak wood (Quercus Ilex), display significantly different bulk carbon chemistry. Ab initio calculations using a modern density functional theory (DFT) code are performed for a suspected subunit of hydrothermal carbon, and highlight the recent advances in calculating XRS spectra from first principals. Furthermore, XRS spectra of two pyrolysis carbons (Pyro-Oak-450, Pyro-Oak-650), produced from the same feedstock at a moderate and severe process temperature, $450{ }^{\circ} \mathrm{C}$ and $650{ }^{\circ} \mathrm{C}$ respectively, highlight a potential route to a quantitative understanding of the bulk average condensation. Comparison of NEXAFS and XRS spectroscopy collected for these materials highlights the advantages of XRS spectroscopy with respect to differences in penetration depth and lack of thickness effects. Finally, this work offers the first reported application of XRS spectroscopy to green carbons, and suggests ways that the technique could bring unparalleled new chemical insight.

\section{Methods and materials}

\subsection{Preparation of green carbons}

2.1.1 Initial preparation. The example lignocellulosic feedstock, Spanish Holm oak (Quercus Ilex), was initially prepared by removing the bark. The de-barked biomass was then milled using a cutting mill (Retsch, Ger.) and separated into the $1.0 \mathrm{~mm}$ to $2.0 \mathrm{~mm}$ size fraction by sieving. The milled and size-separated biomass was dried at $105{ }^{\circ} \mathrm{C}$ for 24 hours before being stored in sealed glass jars.

2.1.2 Hydrothermal carbonisation. Hydrothermal carbonisation of the biomass feedstock was performed in a modified two litre high-pressure batch autoclave (Parr, USA). The temperature of the autoclave was controlled by a thermocouple, located on the inner wall, connected to a proportional-integralderivative (PID) controller (Parr, USA). The PID controller was tuned to avoid temperature overrun and to ensure consistency of the heating profile. For each run, the biomass and water (DDI, $\geq 18 \mathrm{M} \Omega$ ) were loaded into a quartz liner. A $10 \%$ solid loading rate was used (96 $\mathrm{g}$ biomass) with a combined mass of $1000 \mathrm{~g}$ per run. Once sealed, the autoclave was heated using a resistance jacket $\left(5^{\circ} \mathrm{C} \mathrm{min}^{-1}\right)$ to a temperature of $250{ }^{\circ} \mathrm{C}$, then held for $1 \mathrm{~h}$ before being removed from the heating jacket and allowed to cool to room temperature. Solid and liquid products from the reaction were separated using qualitative filter paper (Grade 3 Whatman, UK). The produced hydrothermal carbon was oven dried at $60{ }^{\circ} \mathrm{C}$ overnight. Hydrothermal carbon yield was calculated as the quotient between the masses of the recovered carbon and the initial feedstock on a dry basis. Yield and elemental analysis of the produced carbons are shown in Table 1.

2.1.3 Pyrolysis. Pyrolysis of the initial woody biomass feedstock was performed using a modified vertical tube furnace with $200 \mathrm{~g}$ of sample. The Sample was loaded into a crucible and placed into the pyrolysis reactor, which was subsequently sealed. The pyrolysis reactor was heated at $8{ }^{\circ} \mathrm{C} \mathrm{m}^{-1}$ to the desired temperature $\left(450{ }^{\circ} \mathrm{C}\right.$ or $\left.650{ }^{\circ} \mathrm{C}\right)$, then maintained for a residence time of $1 \mathrm{~h}$ under nitrogen gas flow $\left(40 \mathrm{ml} \mathrm{min}{ }^{-1}\right)$. After the residence time had expired, the reactor was allowed to cool naturally before the samples were removed, weighed and stored in glass vials. Pyrolysis yield was calculated as the quotient between the mass of the recovered carbon and the initial feedstock on a dry basis. Yield and elemental analysis of the produced carbon are shown in Table 1.

Table 1 Yield and elemental analysis of produced carbons and oak feedstock

\begin{tabular}{llllllllll}
\hline & \multicolumn{3}{c}{ Component } & & & & & \multicolumn{2}{c}{ Atomic ratio } \\
\cline { 2 - 4 } Sample & Yield & $\mathrm{C}$ & $\mathrm{H}$ & $\mathrm{N}$ & $\mathrm{O}$ & & $\mathrm{H}: \mathrm{C} \times 10$ & $\mathrm{O}: \mathrm{C}$ \\
\hline Oak wood & - & 48.9 & 7.8 & 1.1 & 37.7 & & 1.6 & 0.8 \\
HTC-Oak-250 & 42.7 & 64.0 & 4.4 & 1.6 & 23.0 & 0.7 & 0.4 \\
Pyro-Oak-450 & 57.4 & 65.7 & 2.7 & 0.6 & 8.9 & 0.4 & 0.1 \\
Pyro-Oak-650 & 25.8 & 76.5 & 1.4 & 0.8 & 7.0 & 0.2 & 0.1
\end{tabular}

\subsection{NEXAFS}

Carbon $K$ edge NEXAFS data was collected between $280 \mathrm{eV}$ and $320 \mathrm{eV}$ using a $120 \mathrm{~nm}$ sized beam at beamline I08 of Diamond Light Source (Oxfordshire, UK). I08 is a scanning transmission $\mathrm{X}$-ray microscopy (STXM) beamline, which also allows larger spot sizes for NEXAFS measurements. Nonetheless, data was collected as a stack scan due to the limitation of the beamline. Samples were prepared by drop-casting small amounts of cryogenically-milled (Retsch, Ger) sample, well-dispersed in ultra-pure water, onto $75 \mathrm{~nm}$ thick $\mathrm{Si}_{3} \mathrm{~N}_{4}$ windows. Image stacks $(4 \times 4 \mu \mathrm{m})$ were acquired with $10 \mathrm{~ms}$ dwell time and $0.15 \mathrm{eV}$ step-size over the main C $K$ edge features ( $283 \mathrm{eV}$ to $300 \mathrm{eV}$ ), and a step-size of $0.5 \mathrm{eV}$ in the energy regions below ( $280 \mathrm{eV}$ to $283 \mathrm{eV}$ ) 
and above ( $300 \mathrm{eV}$ to $320 \mathrm{eV}$ ) the NEXAFS region. As-received signals were converted to optical density using incident signal $\left(I_{0}\right)$ measurements from an adjacent, empty region of the image. Spectra were averaged over a user-defined region-of-interest in the MANTIS software. ${ }^{20}$

\subsection{XRS spectroscopy}

XRS spectroscopy was performed using the lower-energy resolution inelastic X-ray scattering (LERIX) spectrometer at sector 20-ID of the Advanced Photon Source (APS), Chicago USA. ${ }^{21}$ At 20-ID, an undulator beamline, a cryogenically-cooled Si(311) double crystal monochromator was used to produce the monochromatic beam. The produced monochromatic beam was focused using the rhodium stripe of a torroidal mirror to an approximate size of $0.5 \times 0.5 \mathrm{~mm}$. The LERIX instrument contains 19 spherically bent crystal analysers $(\mathrm{R}=1 \mathrm{~m})$ in the vertical scattering plane at $9^{\circ}$ intervals, each subtending a solid angle of $8.3 \times 10^{-3} \mathrm{sr}^{21}$ Opposite each analyser crystal is a NaI scintillator detector, with the sample-analyser-detector positions lying on the Rowland circle geometry. The analyser crystals were tuned at the $\mathrm{Si}(555)$ reflection to maximise the elastic scattering profile for a nominal X-ray energy of $9.8915 \mathrm{keV}$. XRS spectra were measured by scanning the incident photon energy and keeping the analyser energy fixed. Each set of energy scans were carried out with at least one corresponding elastic scan to monitor possible drifts in incident beam energy. This approach results in the uncertainty of the extracted energy loss scale being less than $100 \mathrm{meV}$ - a near-exact energy calibration. The LERIX sample chamber was flushed with helium gas to reduce airscattering from the beam. In order to mitigate beam damage, the sample was pressed into a $13 \mathrm{~mm}$ pellet and rotated on a spinner, then set to a shallow angle in order to spread the beam across the sample. Data were analysed programmatically using a python script written as a module for the XRStools software (see ESI $\dagger)^{22}$ This module (i) adjusts for monochromator drift using the elastic peak, (ii) evaluates the energy resolution for each detector and (iii) converts the abscissa of the spectra from incident energy to the energy-loss scale by subtraction of the centroid energy of the elastic peak from the raw data for each analyser. The data presented in this study were taken from the first 7 analysers $\left(9^{\circ}\right.$ to $\left.63^{\circ}\right)$, representing an average momentum transfer of $4.5 \AA^{-1}$. The energy resolution of the averaged signals from the first 7 analysers $\left(9^{\circ}\right.$ to $\left.63^{\circ}\right)$ were calculated by quadrature from the resolution of the individual analysers for each scan. The average energy resolution of the collected data was $0.63 \mathrm{eV}$. Background subtraction of energy-loss spectra was carried out in XRStools using paramterised Pearson VII functions guided by a HartreeFock calculated core atomic carbon $K$ edge profile.

\subsection{Spectral fitting and XRS DFT calculations}

2.4.1 Spectral fitting. Spectral fitting of the collected XRS spectroscopy data was undertaken using Gaussian non-linear least-squares fitting in the LMFIT software. ${ }^{23}$ Five Gaussian functions were selected with their centroid energy positions set as those of key carbon functional groups taken from literature and reference samples; shown in Table 2.
Table 2 Key electron transition energies, with references, used in the analysis of collected XRS carbon $K$ edge spectra. Absorbing carbon atom is emboldened

Transition

energy (eV) Functional interpretation Transition Ref.

\begin{tabular}{llll}
\hline 285.0 & C $=$ C aromatic & $1 \mathrm{~s}-\pi^{*}$ & $7,8,14$ and 24 \\
286.6 & C $=$ C-O furan & $1 \mathrm{~s}-\pi^{*}$ & 14,16 and 25 \\
287.7 & C-O phenolic, C-H aliphatic & $1 \mathrm{~s}-\pi^{*}, 1 \mathrm{~s}-\sigma^{*}$ & 16 and 26 \\
288.9 & $\mathrm{C}=\mathrm{O}-\mathrm{OH}$ carboxyl/aldehyde & $1 \mathrm{~s}-\pi^{*}$ & 14,25 and 27 \\
290.3 & $\mathrm{C}=\mathrm{O}-\mathrm{X}$ carbonyl & $1 \mathrm{~s}-\pi^{*}$ & 14,25 and 27 \\
292.0 & $\mathrm{C}=\mathrm{C}$ aromatic & $1 \mathrm{~s}-\sigma^{*}$ & 28 and 29
\end{tabular}

During fitting, the full-width-half-maxima (FWHM) of the five main Gaussian functions were initially set as the average energy resolution of the recorded spectra $(0.63 \mathrm{eV})$, then allowed to vary during the fit. The ionisation potential is represented by the product of an exponential and an error function as described by Stohr et al., and fixed at $289 \mathrm{eV} .^{30}$ The error function step was chosen to be fixed at $289 \mathrm{eV}$ to best represent the edge step and background above the edge. The decaying fine-structure region of the spectra, above $300 \mathrm{eV}$, was simulated by two non-symmetric Gaussian functions as discussed by Outka et al. ${ }^{31}$ Further details of the fitting may be found within the ESI. $\dagger$

2.4.2 XRS DFT calculations. For the hydrothermal carbon, theoretical XRS spectra were calculated for a series of furfurylfuran moieties (structure00, structure01 \& structure02) and levulinic acid (Fig. 1). Molecular structures were initially constructed in Avogadro 1.1.1. ${ }^{32}$ Ground state geometry optimisation calculations for these structures were carried out using the ORCA 4.0 code with a B3LYP functional, def2-SVP basis set ${ }^{33}$ and third order dispersion correction with Becke-Jones damping (D3BJ). ${ }^{34,35}$ To reduce computational expense, the RIJCOSX approximation was used with appropriate def2-SVP/J basis sets. ${ }^{36}$ Frequency calculations were run on the optimised structures to ensure that they corresponded to the global energy minimum. Using the ERKALE software, density functional theory (DFT) calculations were performed in order to calculate theoretical XRS spectra. ${ }^{37}$ For all atoms, other than the absorbing atom, triple- $\zeta$ basis functional calculations were applied. For the absorbing carbon atom, augmented IGLO-III basis functions were applied (1 DFT calculation per absorber). ${ }^{38}$ Spectra were calculated for the average experimental momentum transfer: $q=4.5 \AA^{-1}$. All spectra were shifted onto a relative energy scale using the delta KohnSham correction scheme, then an additional rigid shift of $+0.46 \mathrm{eV}$ was used in order to match the energy scale of the experimental spectra. A Gaussian broadening scheme was applied to the computed spectra to mimic the continuum states. ${ }^{39}$

\section{Results and discussion}

X-ray Raman scattering, the physical process underpinning XRS spectroscopy, is non-resonant inelastic X-ray scattering from core electrons. ${ }^{40}$ Despite both being energy-loss techniques, XRS spectroscopy should not be confused with Raman spectroscopy in the optical regime. XRS spectroscopy provides access 

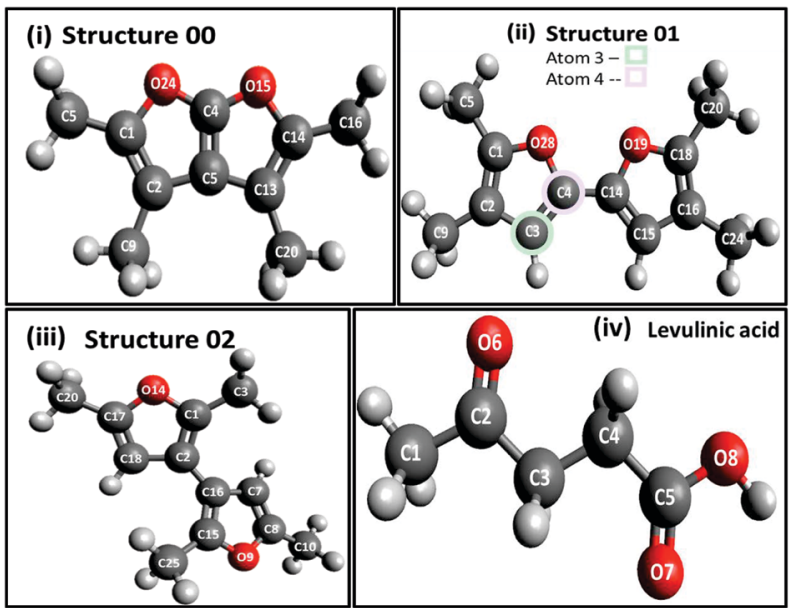

Fig. 1 Labelled representations of calculated molecular structures. (i) Structure 00: a furan-furfuryl moiety linked by a $\pi$ bonding system, representing condensed furan-type units. (ii) Structure 01: a furan-furfuryl moiety with carbon atoms $3(\alpha-C)$ and $4(\beta-C)$ highlighted, representing linking by the $\alpha$ carbon position. (ii) Structure 02: a furan-furfuryl moiety representing linking by the $\beta$ carbon position. (iv) Levulinic acid. [Hydrogen; grey, carbon; black, oxygen; red].

to element-specific core photo-absorption edges of low $Z$-elements (e.g. $K$-edges of $\mathrm{C} \sim 285 \mathrm{eV}, \mathrm{N} \sim 410 \mathrm{eV}, \mathrm{O} \sim 543 \mathrm{eV}$ ), by applying hard (e.g. 6-15 keV) X-ray photons. ${ }^{41}$ The measured quantity is the dynamic structure factor $S(\mathbf{q}, \omega)$, which at low momentum transfer can be shown to be dominated by dipolar transitions, similar to the $\mathrm{X}$-ray photoabsorption cross section. Consequentially, at low momentum transfer, XRS spectroscopy produces equivalent spectra to conventional X-ray photoabsorption spectroscopy. ${ }^{22,40}$ The use of hard X-rays provides bulk spectroscopy and allows for complex sample environments (e.g. pressure cells) to be used. This is because hard X-rays have path-lengths of up to several millimetres in low- $Z$ materials, making them several orders of magnitude more penetrative than soft X-rays which are absorbed within a $100 \mathrm{~nm}$ of the surface. Nevertheless, XRS spectroscopy requires brilliant synchrotron sources to produce large enough flux to generate statistically significant signal within a reasonable scan time, especially for low-concentration samples. Furthermore, the lower energy resolution of XRS spectroscopy leads to a direct trade-off between energy resolution against penetration depth, sample environment and dose. Until recently these drawbacks restricted the application of XRS spectroscopy. However, with the increasing accessibility of third generation synchrotron radiation facilities, XRS spectroscopy is emerging as a powerful technique. This is especially true for green carbons, where the low sensitivity issue is easily overcome, since these materials are usually $60-90 \mathrm{wt} \%$ carbon. Future advances in spectrometer design (e.g. X-ray analyser crystals) are likely to result in faster scan times and improved energy resolution.

\subsection{Bulk chemical differences between hydrothermal and pyrolysis carbon}

Fig. 2 shows the normalised XRS spectra for the hydrothermal carbon (HTC-Oak-250), pyrolysis carbon (Pyro-Oak-450) and their corresponding difference spectrum; the carbon core

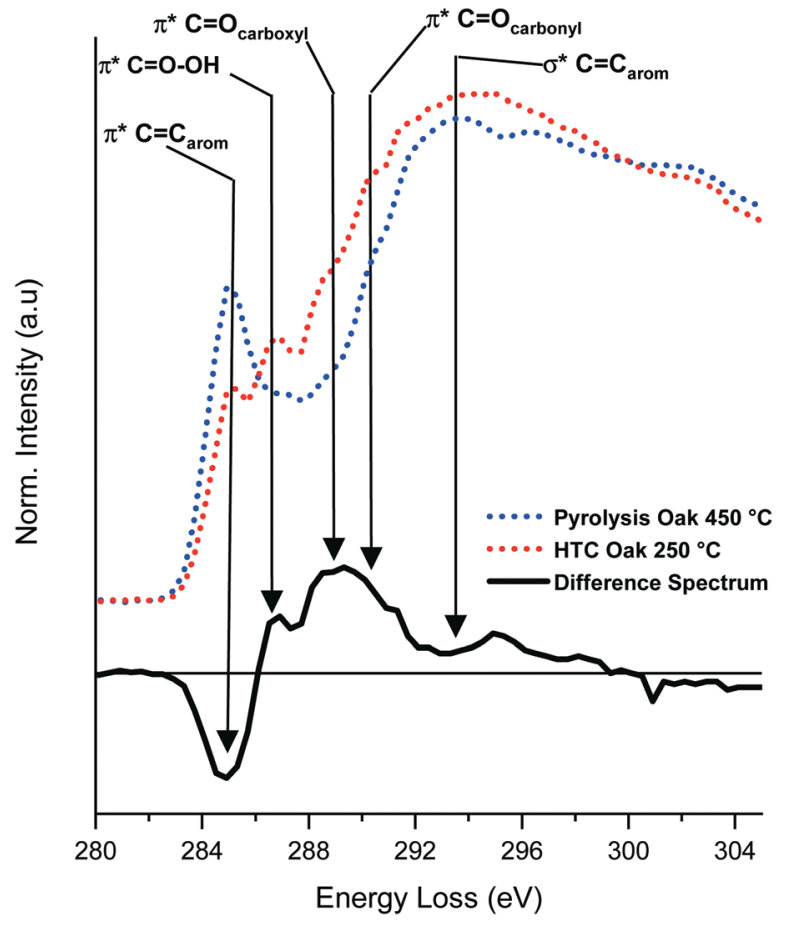

Fig. 2 Background corrected and normalised XRS spectra of pyrolysis (blue dashed) and hydrothermal (red dashed) carbon. Difference spectrum shown below (black solid).

electron transitions (Table 2) are also highlighted. In this section we compare and contrast differences in the bulk carbon functionality of HTC-Oak-250 and Pyro-Oak-450 using XRS spectroscopy. These materials were chosen for such a comparison due to the similarity in their atomic percentage of carbon (Table 1), and therefore relative degree of carbonisation.

3.1.1 Aromatic substructure (285.0 eV and 292-295 eV). In both spectra (Fig. 2), the lowest energy feature is the aromatic C 1s- $\pi^{*}$ arom transition ( $285.0 \mathrm{eV}$ ), where an amplitude loss between HTC-Oak-250 and Pyro-Oak-450 is observed in the difference spectrum. The presence of the aromatic C $1 \mathrm{~s}-\pi^{*}$ arom transition in both experimental XRS spectra confirms that Pyro-Oak-450 and HTC-Oak-250 contain bulk aromatic substructure, which has been reported for other pyrolysis and hydrothermal carbons. ${ }^{10,13,16}$ The FWHM for the Gaussian fit of the aromatic C $1 \mathrm{~s}-\pi^{*}$ arom transition $(285.0 \mathrm{eV}$ ) in Pyro-Oak-450 (Table 3) was found to be $1.85 \pm 0.04 \mathrm{eV}$ and indicates a broad range of aromatic functionality. In contrast, HTC-Oak-250 shows a smaller amplitude and FWHM $(1.24 \pm$ $0.02 \mathrm{eV}$ ) for the same C $1 \mathrm{~s}-\pi^{*}$ arom transition. The smaller amplitude and FWHM of the C $1 \mathrm{~s}-\pi^{*}$ arom transition in the hydrothermal carbon suggests that the bulk aromatic substructure is less well developed in hydrothermal carbon. Furthermore, Pyro-Oak-450 displays increased spectroscopic structure at the $1 \mathrm{~s}-\sigma^{*}$ arom transition ( $292 \mathrm{eV}$ to $295 \mathrm{eV}$ ), which has been shown to indicate more ordered, polyaromatic structures such as polyaromatic hydrocarbons (PAHs). ${ }^{42}$ Taken together, the broader FWHM of the Pyro-Oak-450 ${ }^{\circ} \mathrm{C}$ $1 \mathrm{~s}-\pi^{*}$ arom transition, and the increased structure at the

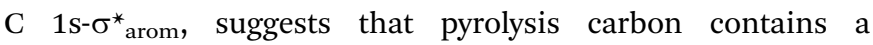


continuum of polyaromatic moieties. This understanding is supported by chemical extractions of pyrolysis carbons performed by Keiluweit et al., which show high levels of extractable PAHs for pyrolysis carbons produced under similar conditions to Pyro-Oak-450. ${ }^{43}$ Increased structure at the $\mathrm{C} 1 \mathrm{~s}-\sigma^{*}{ }_{\text {arom }}$ transition is absent in HTC-Oak-250 which, combined with the smaller FWHM of the C $1 \mathrm{~s}-\pi^{*}$ arom transition, is indicative of fewer aromatic bonding positions and greater structural disorder.

3.1.2 Carboxylic functionality and lignocellulosic recalcitrance (288.9-290.3 eV). In Fig. 2 the shoulder at $(\sim 288.9 \mathrm{eV})$, representing carboxylic functionalities, is present in HTC-Oak250 but absent in Pyro-Oak-450. Lower amplitude in the $287 \mathrm{eV}$ to $290 \mathrm{eV}$ region, suggests that Pyro-Oak-450 has significantly less carboxylic functionality than the hydrothermal carbon. The XRS spectra for both HTC-Oak-250 and Pyro-Oak-450 also exhibit a shoulder at $\sim 290.3 \mathrm{eV}$, which is assigned to the $\mathrm{C} 1 \mathrm{~s}$ $\pi^{*} \mathrm{COO}^{-}$transition. This feature is most likely due to remaining bulk cellulosic functionality from the starting lignocellulosic biomass. ${ }^{14}$ Since XRS spectroscopy is sensitive to changes in bulk chemistry due to the use of hard X-ray photons, a complimentary comparison with surface-sensitive, soft X-ray NEXAFS spectroscopy was conducted.

\subsection{Comparison of NEXAFS and XRS spectroscopy}

As discussed in Section 1, NEXAFS is a powerful technique for understanding local structure and chemistry in low $Z$ materials. However, NEXAFS is limited by the penetration depth of $\mathrm{X}$-rays at lower energies, and the subsequent need for vacuum conditions, which limit experimental design. XRS spectroscopy is able to reproduce the same information as NEXAFS but with three key advantages: (i) bulk sensitivity (ii) absence of spectral saturation due to self-absorption and (iii) increased experimental versatility (e.g. high pressure and other non-vacuum environments). In order to qualify the differences between XRS spectroscopy and soft X-ray absorption spectroscopy, NEXAFS and XRS were performed for the same three green carbons: Pyro-Oak-650, Pyro-Oak-450 and HTC-Oak-250.

3.2.1 Pyro-Oak-450 and Pyro-Oak-650. Fig. 3 shows both the XRS and NEXAFS spectra for Pro-Oak-650 and Pyro-Oak-450. Whilst the NEXAFS and XRS spectra for the pyrolysis carbons are similar, there are some key differences. In Pyro-Oak-650 the $1 \mathrm{~s}-\pi^{*}$ arom transition $(\sim 285 \mathrm{eV})$ is reduced in magnitude in the NEXAFS compared to the bulk-sensitive XRS spectrum. This in in contrast to Pyro-Oak-450, where the NEXAFS and XRS spectra display similar magnitude at the $1 \mathrm{~s}-\pi^{*}$ arom transition. As will be discussed further in Section 3.4.2, the FWHM for the $1 \mathrm{~s}-\pi^{*}$ arom transition has been shown to be linked with the total aromatic condensation of the material. ${ }^{44}$ It is possible that the reduced amplitude and FWHM of the NEXAFS $1 s-\pi^{*}$ arom transition for Pyro-Oak-650 highlights a more disordered surface layer, with a reduced polyaromatic component compared to the bulk material. This might also indicate that Pyro-Oak-450 displays a similar level of aromatisation throughout the whole material.

Despite this, at the $1 \mathrm{~s}-\sigma^{*}$ arom transition, there is increased structure and intensity in the NEXAFS spectrum for Pyro-Oak-

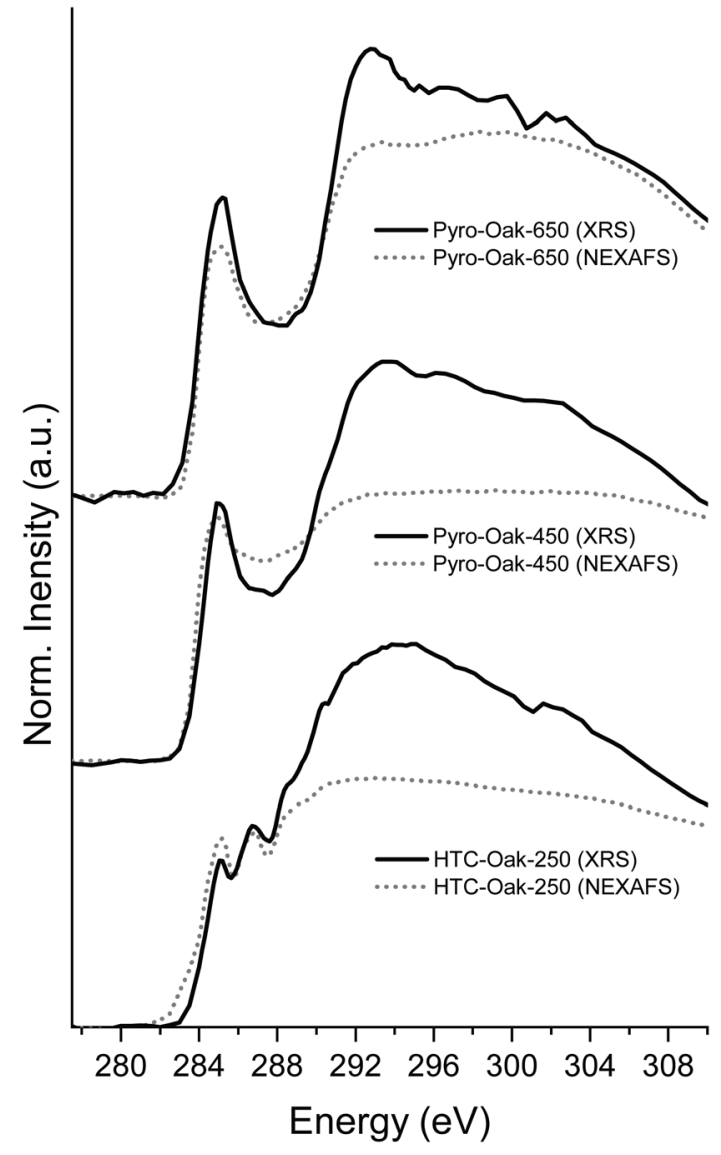

Fig. 3 Comparison of soft X-ray NEXAFS (grey, dashed) and hard XRS spectroscopy (black, solid) for Pyro-Oak-650 (top), Pyro-Oak-450 (middle) and HTC-Oak-250 (bottom).

650 relative to Pyro-Oak-450. This is evidence that Pyro-Oak-650 is more turbostratically aligned, as expected. Relative to the XRS spectrum, the NEXAFS spectrum for Pyro-Oak-450 displays an increase in intensity in the $\mathrm{C}-\mathrm{O}$ region $(286 \mathrm{eV}$ to $289 \mathrm{eV})$. This is due to the surface of Pyro-Oak-450 containing more oxygenated functionalities, not present in the bulk material. Interestingly, increased $\mathrm{C}-\mathrm{O}$ functionality is not observed in the Pyro-Oak-650 NEXAFS spectrum. It is likely that oxygenated surface functionalities are removed at higher pyrolysis temperatures through decarboxylation reactions. The XRS spectrum for Pyro-Oak-450 also exhibits a shoulder at $\sim 290.3 \mathrm{eV}$, which is assigned to the $\mathrm{C} 1 \mathrm{~s}-\pi^{*} \mathrm{COO}^{-}$transition. This shoulder is known to be present in lignocellulosic materials, and is not present in the NEXAFS for either Pyro-Oak-450 or Pyro-Oak-650. The lack of a shoulder at $\sim 290.3 \mathrm{eV}$ in the NEXAFS indicates that lignocellulosic functionality remains in the bulk, despite the surface being fully carbonised.

3.2.2 HTC-Oak-250. The NEXAFS spectrum for HTC-Oak250 displays increased amplitude in the $1 \mathrm{~s}-\pi^{*}$ arom aromatic region. This increased amplitude is likely due to HTC-Oak250 having a surface layer with more aromatic functionality compared to the bulk material. This is supported by a recent $\mathrm{X}$-ray microscopy and spectroscopy study by our group on the surface properties of hydrothermal carbon, which also 
found that the surface was enriched in aromatic functionality compared with the bulk material. ${ }^{18}$

3.2.3 Possible spectral distortion. Qualitative trends between the NEXAFS and XRS spectra clearly show the difference between the carbon chemical signature of the surface compared with the bulk. However, we recognise the possibility of spectral distortions arising from thickness effects commonly observed in transmission mode NEXAFS. Hence, here we refrain from quantifying the comparison between NEXAFS and XRS spectra. It is unlikely that potential distortion here are due to pinhole effects caused by sample inhomogeneity, since no significant spectral changes between regions within the total averaged stack were found (Fig. S1, ESI $\dagger$ ). In the XRS data, peak height ratios may be effected by $q$-dependence effects, due to averaging over momentum transfers up to $4.5 \AA^{-1}$. However, calculations of XRS $q$-dependence for the levulinic acid standard (Fig. S2, ESI $\dagger$ ) do not show any significant changes at higher momentum transfers for energies above 290 eV. Finally, whilst NEXAFS spectra do have much higher spectral resolution $(\sim 100 \mathrm{meV})$ than the collected XRS spectra, the XRS energy resolution appears sufficient to resolve all the key features of the carbon $K$ edge.

\subsection{Hydrothermal carbon - in silico simulations of relevant molecular structures}

3.3.1 Accuracy of DFT calculations. In order to test the accuracy of the DFT calculations discussed in this section, calculated spectra were compared to their corresponding experimental standard. The XRS spectrum collected for levulinic acid and its calculated spectrum are shown in Fig. 4.

After the application of a rigid shift of $+0.46 \mathrm{eV}$, as discussed in Section 2.4.2, the calculated aromatic $1 \mathrm{~s}-\pi^{*}$ arom transition is well aligned with the experimental data. The calculation also

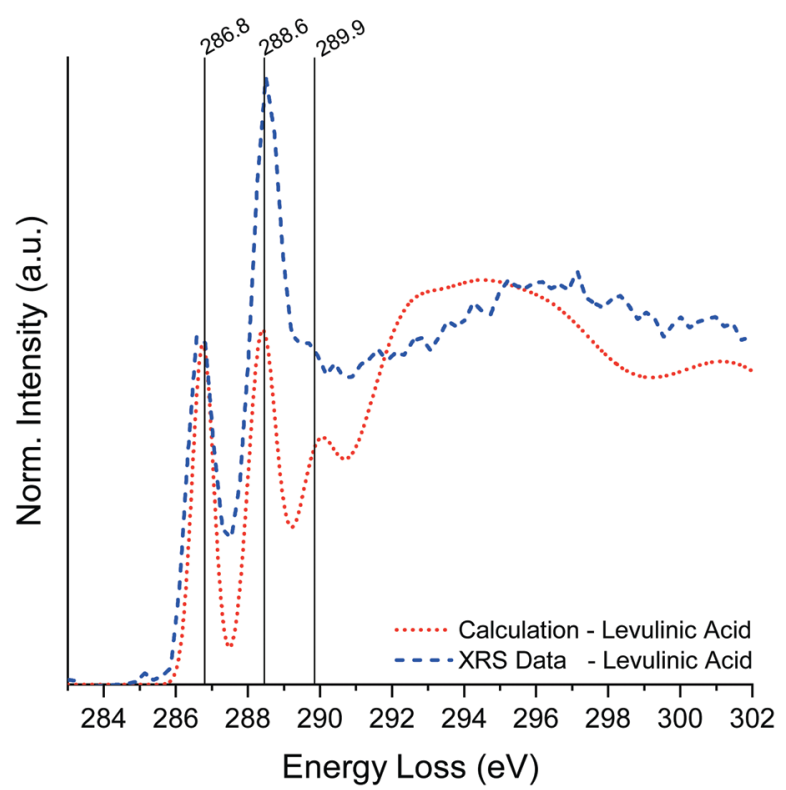

Fig. 4 Experimental XRS spectrum for Levulinic acid (blue, dashed) and average calculated spectra for levulinic acid (red, dotted). matches the energy of the major $1 \mathrm{~s}-\pi^{*}$ furan transition at $286 \mathrm{eV}$ from experiment. Whilst the experimental energy transitions for levulinic acid are well matched by the calculation, it can be seen the relative intensities of the calculation do not match experiment. Currently, quantitative analysis using Gaussian functions is still preferred over the use of component analyses using simulated spectra from DFT calculations.

3.3.2 Hydrothermal carbon proposed structure. From the difference spectrum (Fig. 2), the largest spectral change between Pyro-Oak-450 and HTC-Oak-250, other than the $1 \mathrm{~s}-\pi^{*}$ arom transition, is a significant peak at $286.6 \mathrm{eV}$, which is present in HTC-Oak-250 but absent from Pyro-Oak-450. During HTC, lignocellulosic biomass is hydrolysed under hotcompressed conditions to form hexoses and pentoses. ${ }^{45}$ These sugars undergo dehydration reactions to form a range of organic acids and furfuryls. From kinetic modelling, hydroxymethylfurfural (HMF) is thought to be the principal monomer, whilst levulinic acid is also important during growth. ${ }^{46}$ In a recent NEXAFS study of model-compound-derived hydrothermal carbon by Latham et al., the transition at $286.6 \mathrm{eV}$ was assigned as the $1 \mathrm{~s}-\pi^{*}$ furan transition for the $\alpha$-carbon $(\mathrm{C}-\mathrm{O})$ atom. ${ }^{7,8}$ This assignment agrees with previous ${ }^{13} \mathrm{C}-\mathrm{NMR}$ studies by Falco et al., who suggest several furan-furyl-type structural sub-units which are congruous with the accepted hydrothermal carbon model. ${ }^{13,47}$

Recent advances in density functional theory (DFT) codes now allow for the $a b$ initio calculation of XRS spectra for simple molecular structures. Here, four of the structural motifs proposed by Falco et al. ${ }^{13}$ (Fig. 1), are modelled to: (i) understand the bulk chemical information obtained from XRS spectroscopy, (ii) compare those with published results using ${ }^{13} \mathrm{C}-\mathrm{NMR}$ and surface-limited soft X-ray spectroscopy, and (iii) highlight the importance of using DFT to simulate theoretical XRS spectra for an unambiguous assignment of peaks from experiment. The four simple structural motifs discussed here are: structure00, structure01 and structure02. These three structures differ by their bridging unit. Structure00 is linked by a condensed $\pi$ system, whilst structure 01 and structure 02 are bridged at the $\alpha$ and $\beta$ carbon positions on the furan ring respectively. Literature is unclear on whether bridging occurs by the $\alpha$ carbon or $\beta$ carbon during hydrothermal growth, which is governed by aldol condensation reactions during formation. ${ }^{9,46}$ In order to investigate which of these bridging types best described the collected experimental data for HTC-Oak-250, XRS spectra were calculated for each of these structures (Fig. 5). The experimental data for HTC-Oak-250 displays four clear spectral features at: $285.0 \mathrm{eV}, 286.6 \mathrm{eV}, 288.9 \mathrm{eV}$ and $290.3 \mathrm{eV}$. The spectral feature at $286.6 \mathrm{eV}$ is well matched by all the potential structures. This is expected since $286.6 \mathrm{eV}$ is the known resonance for furan species (Table 2). Structure00 displays a low energy feature at $285.1 \mathrm{eV}$ and higher energy feature at $288.0 \mathrm{eV}$. This low energy feature is also displayed as a shoulder in structure02. However, the relative energy difference between the lower energy feature and the common furan resonance is not well matched to the experimental data for either structure00 or structure 02 .

The experimental relative energy difference between the lower energy peak $(285.1 \mathrm{eV})$ and furan peak $(286.6 \mathrm{eV})$ in the 


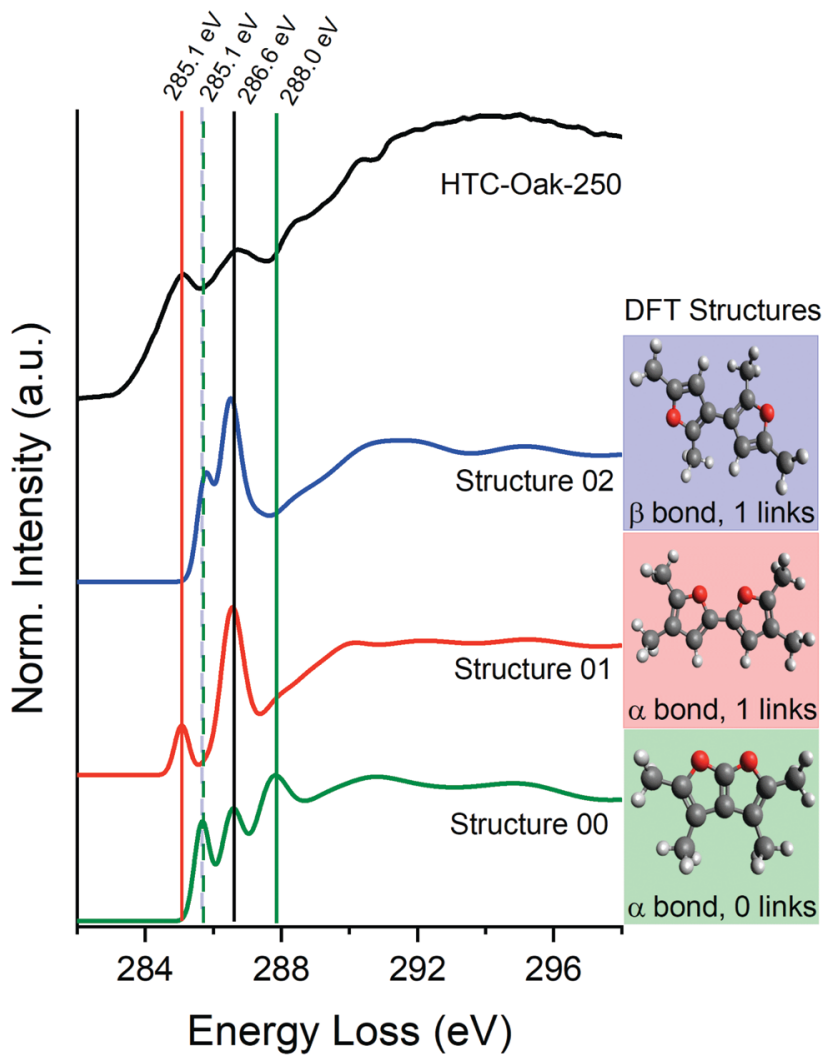

Fig. 5 Experimental XRS spectrum for HTC-Oak-250 and average calculated spectra for: structure00, sturcture01 and structure02.

experimental data is best matched by the calculation for structure01. Fig. 6 displays the average calculated spectra and atom-wise calculated spectra for the $\alpha$-carbon (atom 4) and $\beta$-carbon (atom 3) atoms in the structure01 model (Fig. 1ii). The average spectra for structure01 (red, solid) is the average over all carbon atoms in the structure, including atoms 3 and 4 . The $\alpha$-carbon (structure01, atom 4) component of the simulated XRS spectra has intensity at the $1 \mathrm{~s}-\pi^{*}$ furan transition, but shows no amplitude in the aromatic region $(285.0 \mathrm{eV})$. Whilst the $1 \mathrm{~s}-\pi^{*}{ }_{\text {arom }}$ transition is solely represented by the $\beta$-carbons in the structure 01 model (e.g. structure01, atom 3 ). As previously discussed, the energy difference between the simulated $\beta$-carbon $(285.0 \mathrm{eV})$ and $\alpha$-carbon $(286.6 \mathrm{eV})$ transitions for structure01 matches the energy difference observed in the experimental data. The accurate representation of the aromatic and furan transition peak positions by the structure 01 model provides supportive evidence for the $1 \mathrm{~s}-\pi^{*}$ furan transition assignment made in soft NEXAFS measurements. ${ }^{8}$ Therefore, it is possible to conclude that the bulk hydrothermal carbon (HTC-Oak-250) is built predominantly of furan units bridged at the $\alpha$-carbon atom position. However, this does not rule out the presence of the other calculated structural motifs, since the resulting hydrothermal carbon is a complex amorphous material which is likely to contain a wide variety of different structural units. The calculation for levulinic acid also represents the experimental resonance at $286.6 \mathrm{eV}$, as well as the feature at $288.9 \mathrm{eV}$. The good fit between experiment

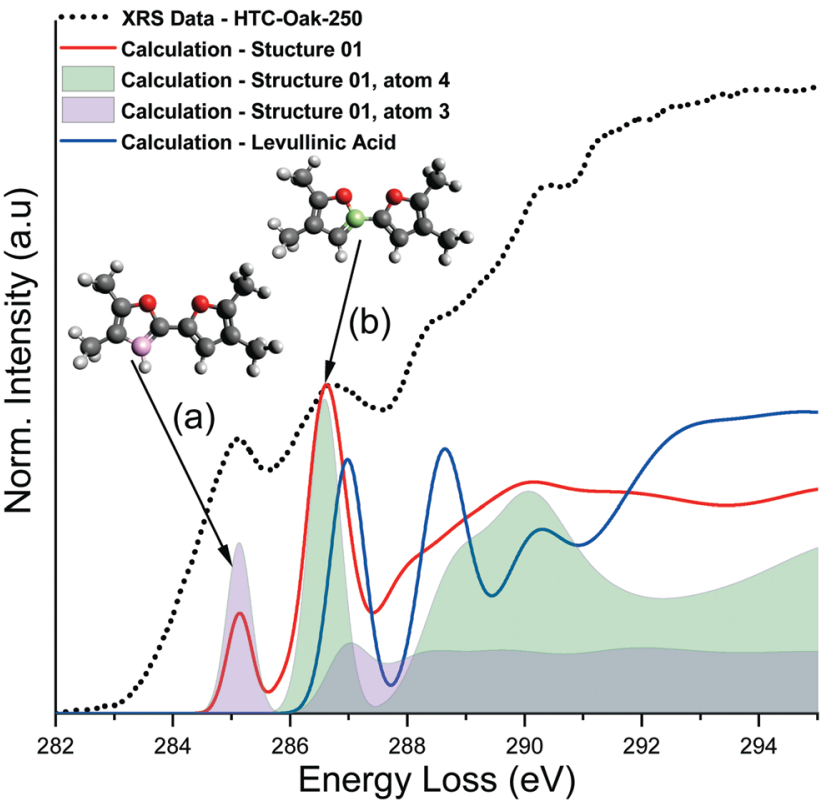

Fig. 6 Experimental XRS spectrum for HTC-Oak-250 (black, dotted) and average calculated spectra for furan-furfuryl moiety: sturcture01 (red, solid) and Levulinic acid (blue, solid). Filled areas show calculated spectra for (a) structure01-atom 3 (green, fill) and (b) structure01-atom4 (pink, fill).

and calculation provides supporting evidence for the role of levulinic acid and other organic acids in the bulk structure of hydrothermal carbon matrix. However, whilst the agreement between theory and experiment for the $\alpha$ carbon bridging model is compelling, the average XRS spectrum calculation of structure 01 fails to reproduce the amplitude ratio between the experimental C $1 \mathrm{~s}-\pi_{\mathrm{arom}^{*}}{ }^{*}$ transition and C $1 \mathrm{~s}-\pi_{\mathrm{furan}}{ }^{*}$ transition peaks. Such differences are likely to be explained by the innate complexity of the material, the presence of additional aromatic functionalities and the associated structural disorder. The final experimental feature at $290.3 \mathrm{eV}$ is not represented by these calculations, and is thought to be due to remaining lignocellulosic functionality within HTC-Oak-250. ${ }^{15}$

\subsection{Evolution in carbon chemistry during pyrolysis}

3.4.1 Interpretation of pyrolysis carbon functionality as a function of temperature. Fig. 7 shows normalised XRS spectra for pyrolysis carbon produced under moderate (Pyro-Oak-450, $450{ }^{\circ} \mathrm{C}$ ) and severe (Pyro-Oak-650, $650{ }^{\circ} \mathrm{C}$ ) pyrolysis temperatures. Fig. 7 also highlights the corresponding difference spectrum and electron transitions for the carbon functionalities shown in Table 2. Initial assessment suggests three main spectral discrepancies between Pyro-Oak-450 and Pyro-Oak650 may be identified: (i) increased amplitude concomitant with broadening at the $\mathrm{C} 1 \mathrm{~s}-\pi^{*}$ arom transition (285 eV, Fig. 7inset), (ii) inhibition of transition amplitudes in the $\mathrm{C}-\mathrm{O}$ spectral region (286 to $290 \mathrm{eV}$ ) and (iii) increased spectroscopic structure in the $\mathrm{C} 1 \mathrm{~s}-\sigma^{*}$ arom transition region $(292 \mathrm{eV})$. In order to investigate these changes in a semi-quantitative manner, Gaussian spectral fitting was performed. Caution must be taken not to over-interpret spectral fitting as precise 


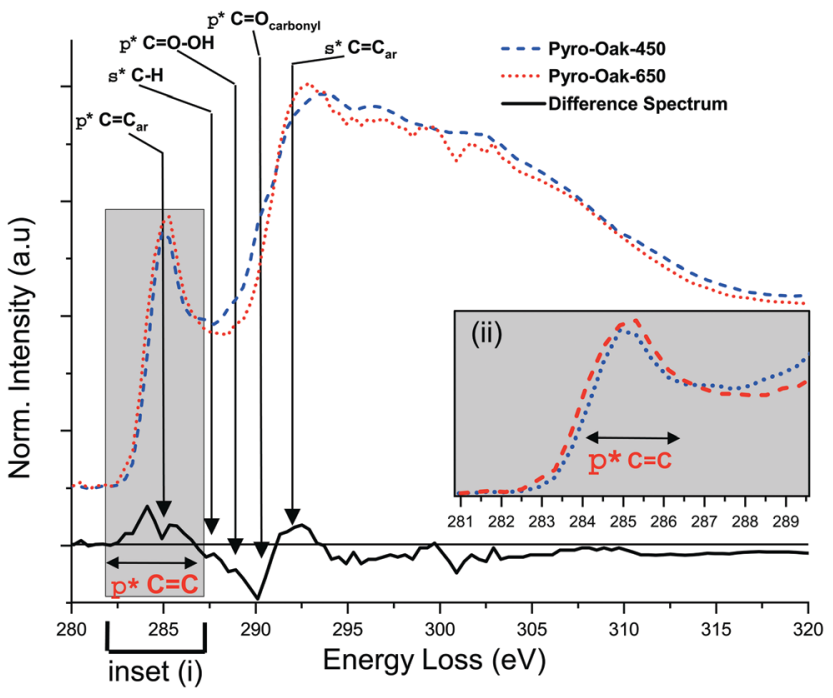

Fig. 7 Background corrected and normalised XRS spectra of pyrolysis carbon produced at two temperatures $\left(450{ }^{\circ} \mathrm{C}\right.$ and $\left.650^{\circ} \mathrm{C}\right)$ are shown with electron transitions highlighted. Difference spectrum shown below in solid black. Inset ii shows the broadening of the $1 \mathrm{~s}-\pi^{\star}{ }_{\text {arom }}$ transition highlighted in grey (inset i).

quantification of functional groups in such a complex material because overlapping contributions from similar compounds may occur in the same energy region. However spectral fitting has been routinely applied to soft X-ray NEXAFS of pyrolysis carbon. ${ }^{16,29,48}$ Here XRS spectra are used to highlight changes in carbon functionality and degree of condensation as a function of pyrolysis temperature. Although, previous NEXAFS studies have been performed on pyrolysis carbon, XRS spectroscopy provides an understanding of chemical changes averaged over the entire sample which are impossible to illustrate using conventionally used surface-limited soft X-ray NEXAFS. ${ }^{43,49,50}$ Fig. 8 shows the results of the non-linear least-squares Gaussian fitting for Pyro-Oak450 and Pyro Oak-650. FWHM and peak areas $\left(A_{\mathrm{g}}\right)$ of the fitted Gaussian transitions are highlighted in Table 3.

From Table 3 , there is a $33 \pm 7 \%$ decrease in $A_{\mathrm{g}}$ at the carboxyl transition (G4, $288.9 \mathrm{eV}$ ) between Pyro-Oak-450 and Pyro-Oak-650. The large decrease in peak $\mathrm{G} 4$ with respect to pyrolysis temperature, indicates decarboxylation reactions to be the dominant mechanism during pyrolysis as suggested by other studies. ${ }^{51}$ The large reduction in the shoulder at G4 contrasts with previous NEXAFS studies of pyrolysis carbons, which show a significant peak at the $\mathrm{C} 1 \mathrm{~s}-\pi^{*}$ arom transition, even at pyrolysis temperatures greater than $500{ }^{\circ} \mathrm{C} .{ }^{43}$ The retention of peak G4 in soft X-ray NEXAFS studies and its absence in this XRS study suggests that carboxylic groups are principally found at the surface of the pyrolysis carbon. Spectral fitting also highlights the complete removal of the carbonyl C $1 \mathrm{~s}-\sigma^{*} \mathrm{COO}^{-}$transition $(\mathrm{G} 5,290.3 \mathrm{eV}$ ) between Pyro-Oak-450 and Pyro-Oak-650. As previously discussed, the $\mathrm{C} 1 \mathrm{~s}-\sigma^{*}{ }_{\mathrm{COO}}^{-}$ transition is a feature present in the spectrum of raw cellulose and other carbohydrates. The removal of peak G5 from the fit indicates complete removal of cellulosic functionality during pyrolysis between $450{ }^{\circ} \mathrm{C}$ and $650{ }^{\circ} \mathrm{C}$. NEXAFS collected here, as well as literature NEXAFS, indicates complete removal of initial cellulosic functionality by $400{ }^{\circ} \mathrm{C}$ at the surface, however this does not seem to be the case in these bulk XRS spectroscopy measurements. ${ }^{14}$ It may well be that the removal of cellulosic functionality begins at the surface, leaving some of this functionality present in the core of pyrolysis carbons. There appears to be little change in both the furan (G2, $286.6 \mathrm{eV}$ ) and phenolic/aliphatic (G3, $287.7 \mathrm{eV}$ ) region of the spectrum between Pyro-Oak-450 and Pyro-Oak-650. It is likely that by $450{ }^{\circ} \mathrm{C}$ any changes in these types of functionalities has already occurred, has reached a stable state or has been completely removed.

3.4.2 XRS spectroscopy for the quantification of bulk aromatic condensation in pyrolysis carbon. Pyrolysis carbon is composed of at least two aromatic carbon phases: (i) an amorphous carbon phase composed of randomly organised aromatic structures and (ii) a turbostratically aligned crystalline phase, comprised of well organised sheets of aromatic 'graphene' layers. ${ }^{52,53}$ Whilst total aromaticity is the total aromatic component of the material, aromatic condensation is only proportional to the disordered aromatic phase. The total aromaticity and aromatic condensation of pyrolysis carbon is important because these values predict the properties of the bulk material. ${ }^{12,50}$ Here, the total aromaticity is estimated by the Gaussian fit of Pyro-Oak-450 and Pyro-Oak-650. The fit shows an increase in peak area $\left(A_{\mathrm{g}}\right)$, and therefore total aromaticity, of $17 \pm 6 \%$ for the $1 \mathrm{~s}-\pi^{*}$ arom transition in Pyro-Oak-650 relative to Pyro-Oak-450 - similar to the total increase in percentage carbon between the materials (Table 1).

Aromatic condensation is more difficult to measure than total aromaticity. Soft X-ray NEXAFS has previously been used to study aromatic condensation in pyrolysis carbons by comparing peak ratios between the $\mathrm{C} 1 \mathrm{~s}-\pi^{*}$ arom transition and the 286 to 288 region. However, Wiedemeier et al. clearly highlight the limitations of this method. ${ }^{50}$ XRS spectra for Pyro-Oak-450 and Pyro-Oak-650 show significant differences to surfacebiased soft X-ray NEXAFS studies in the $286 \mathrm{eV}$ to $288 \mathrm{eV}$ range. These differences are likely due to differences in surface and bulk chemistry, which would distort any quantification of total aromaticity.

Here, XRS spectroscopy is suggested as an alternate route to measuring total aromaticity. XRS spectroscopy is more sensitive to a highly delocalised, poly-condensed $\pi$ electron systems than ${ }^{13} \mathrm{C}-\mathrm{NMR}$. In order to study the bulk degree of condensation in pyrolysis carbons, the Clar model is used. ${ }^{54}$ In the Clar model, $\pi$ bonding in condensed systems is considered as a superposition of aromatic sextets (AS) and isolated double bonds (IDB). AS contain electrons fully delocalised over the arene ring and are highly condensed, stable systems; AS may be considered as equivalent to the crystalline phase of the pyrolysis carbon model. Whilst IDB may be considered as the disordered aromatic phase. It is possible to directly quantify the degree of average bulk condensation for a material in terms of the ratio between IDB and AS (IDB:AS). In an XRS spectroscopy study of polyaromatic hydrocarbons, Bergmann et al. demonstrated direct proportionality between IDB:AS and the FWHM of the 
Table 3 Results of non-linear least squares fitting. Peak area $\left(A_{\mathrm{g}}\right)$ and FWHM for each of the six pre-ionisation potential carbon functionalities are shown

\begin{tabular}{|c|c|c|c|c|c|c|c|c|c|c|c|c|}
\hline imple & \multicolumn{2}{|c|}{$\mathrm{G} 1285.0 \mathrm{eV}$} & \multicolumn{2}{|c|}{ G2 $286.6 \mathrm{eV}$} & \multicolumn{2}{|c|}{ G3 $287.7 \mathrm{eV}$} & \multicolumn{2}{|c|}{ G4 $288.9 \mathrm{eV}$} & \multicolumn{2}{|c|}{ G5 $290.3 \mathrm{eV}$} & \multicolumn{2}{|c|}{ G6 $292.0 \mathrm{eV}$} \\
\hline Pyro-C & $2.17(4)$ & $1.85(4)$ & $0.66(8)$ & 1.48 & $0.61(3)$ & 1.62 (fixe & $0.42(1)$ & 1.62 (fixed) & 0.4 & 1.6 & $1.48(5)$ & 2.43( \\
\hline
\end{tabular}

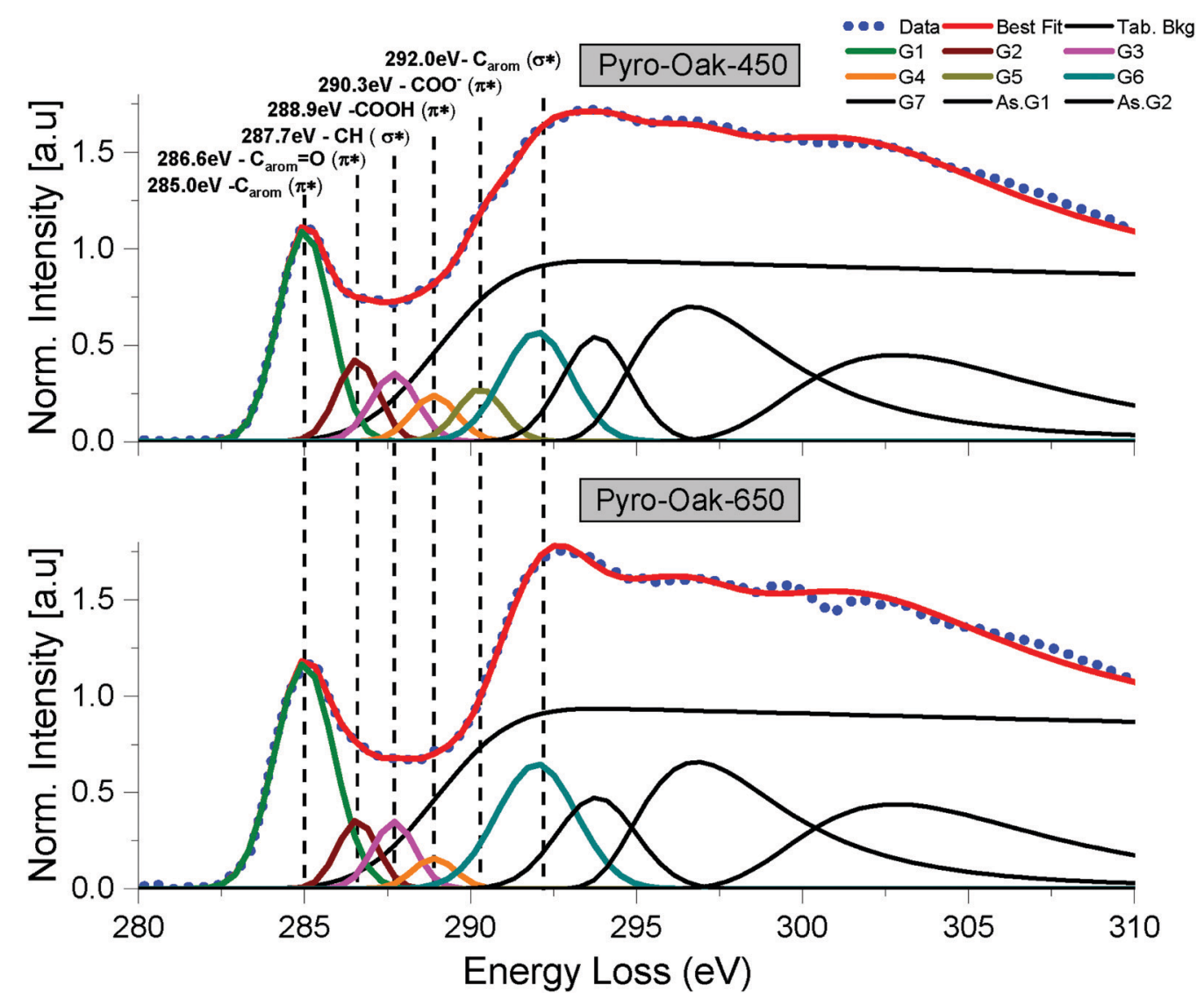

Fig. 8 Spectral fitting of two pyrolysis carbons produced at $650{ }^{\circ} \mathrm{C}$ (Pyro-Oak-650) and $450{ }^{\circ} \mathrm{C}$ (Pyro-Oak-450) using non-linear least-squares fitting. The pre-ionisation potential (pre-IP) region is represented using six Gaussian functions, the IP is represented using a decaying step function, and the post-IP region is represented using two asymmetric functions and one symmetric Gaussian function.

aromatic $1 \mathrm{~s}-\pi^{*}$ arom $(\mathrm{G} 1,285 \mathrm{eV})$ transition. ${ }^{42,44}$ Here, we suggest that the ratio of IDB:AS is able to quantify the degree of aromaticity in green carbons via the measurement of FWHM of the $\mathrm{C} 1 \mathrm{~s}-\pi^{*}$ arom transition. In the fitting presented here, the FWHM of Pyro-Oak-450 and Pyro-Oak-650 were found to be $1.85 \mathrm{eV}$ and $2.10 \mathrm{eV}$ respectively. Using published data as a reference, the IDB:AS ratio for Pyro-Oak-450 and Pyro-Oak-650 were estimated to be approximately 0.7 and 1.0 respectively using this method. ${ }^{42,44}$ Through this method, XRS spectroscopy offers an alternative route to measure total aromaticity in complex, disordered carbonaceous materials, including those which are not suitable for ${ }^{13} \mathrm{C}-\mathrm{NMR}$.

\subsection{Implications of XRS spectroscopy on green carbon chemistry}

In this study XRS spectroscopy provides an alternative to ${ }^{13} \mathrm{C}-\mathrm{NMR}$ and soft X-ray NEXAFS for the bulk investigation of local structure and chemistry in green carbon. XRS facilities are now increasingly available at modern synchrotron radiation facilities. $^{21,55-58}$ In this section we briefly outline selected research directions where XRS could provide significant insight into green carbon.

The complexity of biomass structures and the large number of intermediates formed during pyrolysis typically require drastic simplifications of mechanistic pathways. ${ }^{59}$ Through understanding chemical pathways governing pyrolysis, it may be possible to produce chars with engineered carbon and inorganic functionalities. ${ }^{3,60}$ This is likely to be important for the application of green carbons as electronic devices such as batteries and supercapacitors. XRS spectroscopy is well-suited for such investigations and has been applied to the intercalation of dopants into graphite and charge transfer within such materials. $^{61}$ 
As already discussed in Section 3.2, the broadening of the $\mathrm{C} 1 \mathrm{~s}-\pi^{*}$ arom transition is potentially a route to a semi-quantitative assessment of bulk aromatic condensation. Our hypothesis for measuring aromatic condensation differs from current NEXAFS methods. In order to validate the use of XRS spectroscopy for bulk carbon condensation reaction mechanisms, a comparison of several samples must be performed and compared against the current gold-standard, ${ }^{13} \mathrm{C}-\mathrm{NMR}$. If successful, the measurement of bulk carbon condensation using XRS spectroscopy could be achieved faster than with ${ }^{13} \mathrm{C}-\mathrm{NMR}$ and for materials not suited to ${ }^{13} \mathrm{C}-\mathrm{NMR}$.

Finally, due to the use of hard X-rays, XRS spectroscopy provides the ability to follow hydrothermal carbon chemistry over time, within the pressurised autoclave. Previous XRS spectroscopy studies have been able to follow in situ bulk carbon chemistry of polymerisation. ${ }^{62}$ Future in situ studies of hydrothermal carbonisation are likely to be able to shed light on the mechanisms governing its formation. In situ XRS spectroscopy studies of pyrolysis might also provide a detailed understanding of the evolution of aromatic condensation as a function of temperature. In conjunction with DFT calculations, in situ XRS spectroscopy will become a powerful tool for studying hydrothermal carbonisation.

\section{Conclusions}

XRS spectroscopy is a powerful bulk spectroscopy technique capable of investigating disordered carbonaceous materials. Here XRS spectroscopy has been applied to two complex, biomass-derived, amorphous green carbon systems: hydrothermal and pyrolysis carbon. The hydrothermal carbon, HTCOak-250 displays less well-developed aromatic substructure than either Pyro-Oak-450 or Pyro-Oak-650. Our results show that pyrolysis carbon is likely to be a continuum of aromatic moieties unlike hydrothermal carbon which exhibits higher local structural disorder. Using the ERKALE DFT code, experimental data was compared with two molecular structures thought to be present in hydrothermal carbon. Comparison of calculation and experiment indicates that (i) the previous assignment of the $286.6 \mathrm{eV}$ furan transition is correct, (ii) hydrothermal carbon is primarily built of furan structures linked via the $\alpha$-carbon position on the furan ring, and (iii) that carboxylic functionality (e.g. levulinic acid) is contained within the bulk hydrothermal carbon structure. Comparison of NEXAFS and XRS spectroscopy supports the presence of an enriched aromatic layer on the surface of hydrothermal carbon.

Pyrolysis carbons produced at a moderate $\left(450{ }^{\circ} \mathrm{C}\right)$ and a severe $\left(650^{\circ} \mathrm{C}\right)$ pyrolysis temperature were compared using XRS spectroscopy. Spectral fitting suggests that decarboxylation appears to be the dominant mechanism between the two pyrolysis temperatures, and that bulk cellulosic functionality present at $450{ }^{\circ} \mathrm{C}$ is removed by $650{ }^{\circ} \mathrm{C}$. These finding were also confirmed through a comparison of NEXAFS and XRS spectroscopy. NEXAFS highlighted a more disordered surface layer in Pyro-Oak-650 with limited oxygenated functionalities, this is in contrast to Pyro-Oak-450, which displays a more oxygenated surface layer. Together the XRS fitting and surface-sensitive NEXAFS data suggest that the oxygenated surface layer in PyroOak-450 is removed through decarboxylation reactions during pyrolysis at $650{ }^{\circ} \mathrm{C}$. When compared to NEXAFS the three key advantages of XRS spectroscopy are: (i) bulk sensitivity (ii) absence of spectral saturation due to self-absorption and (iii) increased experimental versatility. However, the transmissionmode NEXAFS reported here suffer from thickness effects, which result in spectral distortion. Further work is required to produce NEXAFS spectra suitable for direct quantification with XRS spectra. Combined with the surface-sensitivity of NEXAFS, the dual application of NEXAFS and XRS provides a promising route for future investigation of carbonaceous materials, where XRS has proved well-suited. Finally, XRS data of pyrolysis carbon are used here to propose an alternative approach for the quantitative measurement of bulk aromatic condensation in green carbons. However, XRS spectroscopy should be used for additional studies to confirm the applicability of our proposed methodology. Some of the burning questions in the area of green carbon chemistry, identified above, may be addressed using XRS spectroscopy.

\section{Conflicts of interest}

There are no conflicts of interest to declare.

\section{Acknowledgements}

This work was supported by the Engineering and Physical Sciences Research Council [EP/L014912/1] as part of the UK Centre for Doctoral Training in Bioenergy at Leeds University. This research used resources of the Advanced Photon Source, an Office of Science User Facility operated for the U.S. Department of Energy (DOE) Office of Science by Argonne National Laboratory, and was supported by the U.S. DOE under Contract No. DE-AC02-06CH11357, and the Canadian Light Source and its funding partners. NEXAFS spectra were collected at beamline I08 of the Diamond Light Source as part of proposal numbers SP19228-1 and MG23583-1. The authors are thankful for the technical support of the beamline scientists at I08: T. Araki, M. Kazemian and B. Kaulich. Assistance in wet chemical analyses by Mr Simon Lloyd and Dr Adrian Cunliffe is gratefully acknowledged. B. M. and L. J. R. H. thank Prof. Andrew B. Ross for helpful discussions.

\section{Notes and references}

1 W.-J. Liu, H. Jiang and H.-Q. Yu, Green Chem., 2015, 17, 4888-4907.

2 M.-M. Titirici, R. J. White, N. Brun, V. L. Budarin, D. S. Su, F. del Monte, J. H. Clark and M. J. MacLachlan, Chem. Soc. Rev., 2015, 44, 250-290.

3 W.-J. Liu, H. Jiang and H.-Q. Yu, Chem. Rev., 2015, 115, 12251-12285. 
4 H. S. Kambo and A. Dutta, Renewable Sustainable Energy Rev., 2015, 45, 359-378.

5 M. Zhang, H. Yang, Y. Liu, X. Sun, D. Zhang and D. Xue, Nanoscale Res. Lett., 2012, 7, 1-13.

6 M. Sevilla and A. B. Fuertes, Carbon, 2009, 47, 2281-2289.

7 K. G. Latham, W. M. Dose, J. A. Allen and S. W. Donne, Carbon, 2018, 128, 179-190.

8 K. G. Latham, M. I. Simone, W. M. Dose, J. A. Allen and S. W. Donne, Carbon, 2017, 114, 566-578.

9 N. Baccile, G. Laurent, F. Babonneau, F. Fayon, M.-M. Titirici and M. Antonietti, J. Phys. Chem. C, 2009, 113, 9644-9654.

10 A. V. McBeath, R. J. Smernik, M. P. Schneider, M. W. Schmidt and E. L. Plant, Org. Geochem., 2011, 42(10), 1194-1202.

11 I. Pastorova, R. E. Botto, P. W. Arisz and J. J. Boon, Carbohydr. Res., 1994, 262, 27-47.

12 A. V. McBeath, R. J. Smernik, E. S. Krull and J. Lehmann, Biomass Bioenergy, 2014, 60, 121-129.

13 C. Falco, F. Perez Caballero, F. Babonneau, C. Gervais, G. Laurent, M.-M. Titirici and N. Baccile, Langmuir, 2011, 27(23), 14460-14471.

14 D. Solomon, J. Lehmann, J. Kinyangi, B. Liang, K. Heymann, L. Dathe, K. Hanley, S. Wirick and C. Jacobsen, Soil Sci. Soc. Am. J., 2009, 73, 1817.

15 A. Gainar, J. S. Stevens, C. Jaye, D. A. Fischer and S. L. M. Schroeder, J. Phys. Chem. B, 2015, 119(45), 14373-14381.

16 K. Heymann, J. Lehmann, D. Solomon, M. W. I. Schmidt and T. Regier, Org. Geochem., 2011, 42(9), 1055-1064.

17 N. Hagemann, S. Joseph, H.-P. Schmidt, C. I. Kammann, J. Harter, T. Borch, R. B. Young, K. Varga, S. Taherymoosavi, K. W. Elliott, A. McKenna, M. Albu, C. Mayrhofer, M. Obst, P. Conte, A. Dieguez-Alonso, S. Orsetti, E. Subdiaga, S. Behrens and A. Kappler, Nat. Commun., 2017, 8, 1089.

18 L. J. R. Higgins, A. P. Brown, J. P. Harrington, A. B. Ross, B. Kaulich and B. Mishra, Carbon, 2020, 161, 423-431.

19 R. Ibbett, S. Gaddipati and G. Tucker, Biomass Bioenergy, 2019, 121, 48-55.

20 M. Lerotic, R. Mak, S. Wirick, F. Meirer and C. Jacobsen, J. Synchrotron Radiat., 2014, 21, 1206-1212.

21 T. T. Fister, G. T. Seidler, L. Wharton, A. R. Battle, T. B. Ellis, J. O. Cross, A. T. Macrander, W. T. Elam, T. A. Tyson and Q. Qian, Rev. Sci. Instrum., 2006, 77, 1-7.

22 C. Sahle, A. Mirone, J. Niskanen, J. Inkinen, M. Krisch and S. Huotari, J. Synchrotron Radiat., 2015, 22, 400-409.

23 M. Newville, R. Otten, A. Nelson, A. Ingargiola, T. Stensitzki, D. Allan, A. Fox, F. Carter, D. Pustakhod, Y. Ram, C. Deil, A. Beelen, O. Frost, N. Zobrist, G. Pasquevich, A. L. R. Hansen, T. Spillane, S. Caldwell, A. Polloreno, A. T. Hannum, J. Zimmermann, J. Borreguero, J. Fraine, B. F. Maier, B. Gamari and A. Almarza, Zenodo, 2014, 1-7.

24 G. D. Cody, R. E. Botto, H. Ade, S. Behai, M. Disko and S. Wirick, Energy Fuels, 1995, 9, 525-533.

25 D. Solomon, J. Lehmann, J. Harden, J. Wang, J. Kinyangi, K. Heymann, C. Karunakaran, Y. Lu, S. Wirick and C. Jacobsen, Chem. Geol., 2012, 329, 53-73.
26 A. C. Scheinost, R. Kretzschmar, I. Christ, C. Jacobsen, I. Christ and C. Jacobsen, Humic Substances, Royal Society of Chemistry, Cambridge, 2001, pp. 39-48.

27 D. Solomon, J. Lehmann, J. Wang, J. Kinyangi, K. Heymann, Y. Lu, S. Wirick and C. Jacobsen, Sci. Total Environ., 2012, 438, 372-388.

28 K. Suenaga and M. Koshino, Nature, 2010, 468, 1088-1090.

29 J. Lehmann, B. Liang, D. Solomon, M. Lerotic, F. Luizão, J. Kinyangi, T. Schäfer, S. Wirick and C. Jacobsen, Global Biogeochem. Cycles, 2005, 19, 1-12.

30 J. Stöhr, NEXAFS Spectroscopy, Springer Berlin Heidelberg, Berlin, Heidelberg, 1st edn, 1992, vol. 25, pp. 211-238.

31 D. A. Outka and J. Stöhr, J. Chem. Phys., 1988, 88, 3539-3554.

32 M. D. Hanwell, D. E. Curtis, D. C. Lonie, T. Vandermeerschd, E. Zurek and G. R. Hutchison, J. Cheminf., 2012, 4, 17.

33 F. Weber, J. Ren, T. Petit and A. Bande, Phys. Chem. Chem. Phys., 2019, 21, 6999-7008.

34 F. Neese, Wiley Interdiscip. Rev.: Comput. Mol. Sci., 2018, 8, 1327. 35 S. Grimme, S. Ehrlich and L. Goerigk, J. Comput. Chem., 2011, 32, 1456-1465.

36 F. Weigend, Phys. Chem. Chem. Phys., 2006, 8, 1057-1065.

37 J. Lehtola, M. Hakala, A. Sakko and K. Hämäläinen, J. Comput. Chem., 2012, 33, 1572-1585.

38 W. Kutzelnigg, U. Fleischer and M. Schindler, NMR Basic Principles and Progress, Berlin, Heidelberg, 1990, pp. 165-262.

39 I. Juurinen, T. Pylkkänen, K. O. Ruotsalainen, C. J. Sahle, G. Monaco, K. Hämäläinen, S. Huotari and M. Hakala, J. Phys. Chem. B, 2013, 117, 16506-16511.

40 W. Shülke, Electron Dynamics by Inelastic X-Ray Scattering, Oxford University Press, Oxford, 7th edn, 2007, vol. 7, p. 186.

41 U. Bergmann, P. Glatzel and S. P. Cramer, Microchem. J., 2002, 71, 221-230.

42 U. Bergmann, H. Groenzin, O. C. Mullins, P. Glatzel, J. Fetzer and S. P. Cramer, Pet. Sci. Technol., 2004, 22, 863-875.

43 M. Keiluweit, P. S. Nico, M. G. Johnson and M. Kleber, Environ. Sci. Technol., 2010, 44, 1247-1253.

44 U. Bergmann, H. Groenzin, O. C. Mullins, P. Glatzel, J. Fetzer and S. P. Cramer, Chem. Phys. Lett., 2003, 369, 184-191.

45 M.-M. Titirici, M. Antonietti and N. Baccile, Green Chem., 2008, 10, 1204.

46 D. Jung, M. Zimmermann and A. Kruse, ACS Sustainable Chem. Eng., 2018, 6, 13877-13887.

47 C. Falco, N. Baccile and M.-M. Titirici, Green Chem., 2011, 13, 3273.

48 F. N. D. Mukome, A. L. D. Kilcoyne and S. J. Parikh, Soil Sci. Soc. Am. J., 2014, 78, 1632-1640.

49 C. P. Chen, C.-H. Cheng, Y.-H. Huang, C.-T. Chen, C.-M. Lai, O. V. Menyailo, L.-J. Fan and Y. W. Yang, Geoderma, 2014, 232-234, 581-588.

50 D. B. Wiedemeier, S. Abiven, W. C. Hockaday, M. Keiluweit, M. Kleber, C. A. Masiello, A. V. McBeath, P. S. Nico, L. A. Pyle, M. P. Schneider, R. J. Smernik, G. L. Wiesenberg and M. W. Schmidt, Org. Geochem., 2015, 78, 135-143.

51 F.-X. Collard and J. Blin, Renewable Sustainable Energy Rev., 2014, 38, 594-608. 
52 A. K. Kercher and D. C. Nagle, Carbon, 2003, 41, 15-27.

53 R. E. Franklin, Proc. R. Soc. London, Ser. A, 1951, 209, 196-218.

54 M. Randić, Chem. Rev., 2003, 103, 3449-3606.

55 S. Huotari, C. J. Sahle, C. Henriquet, A. Al-Zein, K. Martel, L. Simonelli, R. Verbeni, H. Gonzalez, M.-C. Lagier, C. Ponchut, M. Moretti Sala, M. Krisch and G. Monaco, J. Synchrotron Radiat., 2017, 24, 521-530.

56 D. Sokaras, D. Nordlund, T.-C. Weng, R. A. Mori, P. Velikov, D. Wenger, A. Garachtchenko, M. George, V. Borzenets, B. Johnson, Q. Qian, T. Rabedeau and U. Bergmann, Rev. Sci. Instrum., 2012, 83, 043112.

57 C. Sternemann and M. Wilke, High Pressure Res., 2016, 36, 275-292.
58 J. M. Ablett, D. Prieur, D. Céolin, B. Lassalle-Kaiser, B. Lebert, M. Sauvage, T. Moreno, S. Bac, V. Balédent, A. Ovono, M. Morand, F. Gélebart, A. Shukla and J. P. Rueff, J. Synchrotron Radiat., 2019, 26, 263-271.

59 E. Ranzi, A. Cuoci, T. Faravelli, A. Frassoldati, G. Migliavacca, S. Pierucci and S. Sommariva, Energy Fuels, 2008, 22, 4292-4300.

60 S. Abiven, M. W. Schmidt and J. Lehmann, Nat. Geosci., 2014, 7, 326-327.

61 M. Balasubramanian, C. S. Johnson, J. O. Cross, G. T. Seidler, T. T. Fister, E. A. Stern, C. Hamner and S. O. Mariager, Appl. Phys. Lett., 2007, 91, 031904.

62 J. Inkinen, J. Niskanen, T. Talka, C. J. Sahle, H. Müller, L. Khriachtchev, J. Hashemi, A. Akbari, M. Hakala and S. Huotari, Sci. Rep., 2015, 5, 15851. 